\title{
Colon wall-oriented endoscopic resection of a giant pedunculated colorectal lesion
}

\author{
Vincent Zimmer ${ }^{\mathrm{a}, \mathrm{b}}$ \\ Marienhausklinik St. Josef Kohlhof, Neunkirchen; Saarland University Medical Center, Saarland University, Homburg, Germany
}

A 48-year-old male was referred for endoscopic resection of a giant pedunculated sigmoid lesion. Endoscopy revealed an estimated 40-mm pedunculated polyp (Paris Ip) with luminal subocclusion (Fig. 1A) and an estimated 2-cm long stalk (Fig. 1B). First, we injected $4 \mathrm{~mL}$ of an indigo carmine-saline mixture into the base (Fig. 1C) and resected precisely at the attachment point to the colonic wall. After ensuring adequate ensnarement into a $35-\mathrm{mm}$ snare by what is called the "traction technique", special attention was paid to very slow snare closure so as to avoid muscularis propria entrapment. Visualization of the wide-field resection bed excluded deep mural injury, but instead indicated ad hoc arterial bleeding from the center of the lesion, representing a large-caliber stalk vessel (Fig. 1D), easily and successfully treated by immediate targeted hemoclipping. The patient followed an uncomplicated clinical course, without occurrence of delayed post-polypectomy bleeding or electrocoagulation syndrome. Macroscopic assessment of the retrieved specimen indicated an adequate colon wall-oriented resection (Fig. 2A) with wide margins (Fig. 2B). Final histopathology likewise confirmed wide R0 resection of a low-grade intraepithelial neoplasia.

Hot snare polypectomy is recommended for pedunculated colorectal lesions, with the discussion typically centering on the prevention of bleeding complications, with or without mechanical hemostasis [1]. In general, electrocautery-based stalk transection one-half to one-third the distance between head and colon wall by standard snares is suggested by experts [2]. However, for "giant" pedunculated lesions $>30 \mathrm{~mm}$, the risks of malignancy and submucosal invasiveness are real, with full optical diagnosis often not achievable because of the size, limited circumferential accessibility and floppiness of the lesions. To this end, although its true clinical potential and procedure-related safety clearly warrant further systematic assessment, colon wall-oriented resection may be considered instrumental in ensuring adequate resection margins. Likewise, the consequential histopathological assessment may follow more convincingly established oncological concepts [3].

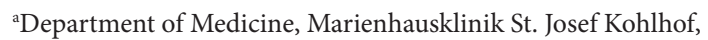
Neunkirchen (Vincent Zimmer); ${ }^{b}$ Department of Medicine II, Saarland University Medical Center, Saarland University, Homburg (Vincent Zimmer), Germany

Conflict of Interest: None

Correspondence to: Dr. Vincent Zimmer, Department of Medicine, Marienhausklinik St. Josef Kohlhof, Klinikweg 1-5, 66539 Neunkirchen, Germany, e-mail: vincent.zimmer@gmx.de

Received 7 June 2020; accepted 11 June 2020; published online 30 June 2020

DOI: https://doi.org/10.20524/aog.2020.0513

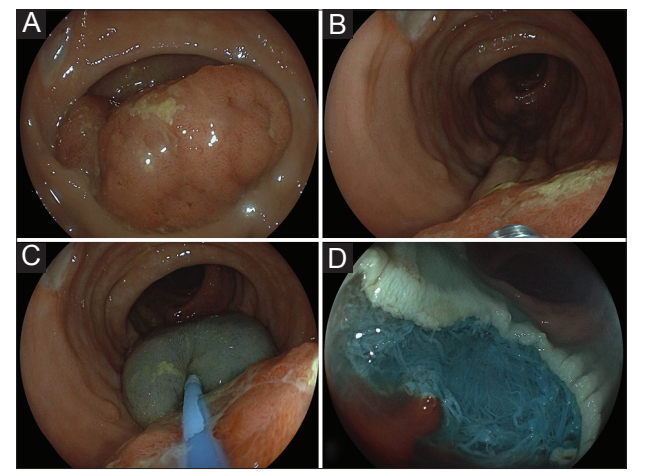

Figure 1 (A) An estimated 40-mm pedunculated lesion (Paris Ip) in the sigmoid with (B) a thick 2-cm long stalk. (C) Submucosal injection into the stalk base, followed by "colon-wall oriented resection" by the so-called traction technique. (D) While post-hoc visualization of the wide-field resection bed excluded deep mural injury, arterial bleeding from the lesion's center, representing a large-caliber stalk vessel, emerged and was treated by targeted hemoclipping

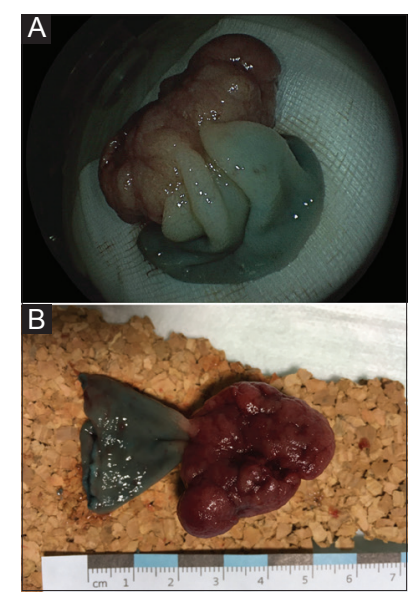

Figure 2 Ex vivo visualization of the retrieved specimen indicated (A) an adequate colon wall-oriented resection with (B) wide margins as confirmed by final histopathology (low-grade intraepithelial neoplasia with wide R0 status)

\section{References}

1. Ferlitsch M, Moss A, Hassan C, et al. Colorectal polypectomy and endoscopic mucosal resection (EMR): European Society of Gastrointestinal Endoscopy (ESGE) Clinical Guideline. Endoscopy 2017;49:270-297.

2. Tholoor S, Tsagkournis O, Basford P, Bhandari P. Managing difficult polyps: techniques and pitfalls. Ann Gastroenterol 2013;26:114-121.

3. Ciocalteu A, Gheonea DI, Saftoiu A, Streba L, Dragoescu NA, Tenea-Cojan TS. Current strategies for malignant pedunculated colorectal polyps. World J Gastrointest Oncol 2018;10:465-475. 